\title{
Rubén Darío: \\ La angustia, una apertura del mundo
}

Erwin Silva

Recibido: 02.08.2014 / Aprobado: 08.09. 2014

\section{RESUMEN}

El presente artículo consisteen un breve análisis ontológico de la angustia en algunos poemas de Rubén Darío, en particular de algunos textos y formas de composición relevante en los que se muestran las preocupaciones y problemas de la existencia humana como el tiempo, la muerte, el dolor y la nada que revela la angustia.

Palabras clave: Ontología, poesía, angustia, existencia, nada.

\section{ABSTRACT}

This article consists of a brief ontological analysis of anguish on some poems by Rubén Darío, in particular of some texts and forms of relevant composition in which show the concerns and problems of human existence, such as time, death, pain and the void that reveals the anguish.

Key words: Ontology, poetry, anguish, existence, the void

(...) "Cuando dije que mi poesía era "mía en mi", sostuve la primera condición de mi existir RD. Canto Errante

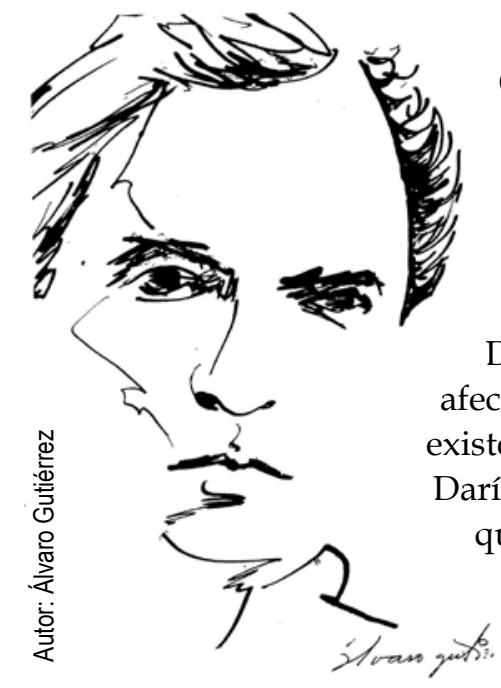

Quizás una de las vías posibles para una lectura distinta del existente humano en la poesía de Rubén Darío, sea ver la angustia como una disposición afectiva originaria que en su poesía es una apertura del mundo que también le permite a $\mathrm{R}$. Darío abrirse a sí mismo. La disposición afectiva está junto al comprender en términos existenciales. Por esto, sostengo que en Rubén Darío no hay una simple dualidad como se ha querido creer sino más bien una ontología de la comprensión que resuelve una tensión del ser manifiesta en el lenguaje. De modo que esas oscilaciones atribuidas a Rubén Darío como que se mueve entre la catedral y las ruinas paganas o entre el fauno y el ángel; no son más que sentimientos o pasiones que se revelan en un mismo ente iluminado por el ser. No son los extremos a los que tiende el péndulo sino tendencias, voluntad, instintos o inclinaciones del existente.

Así que calificar de existencial a la poesía de Rubén Darío es superficial e impreciso sin mostrar siquiera el sustrato ontológico que subyace en su poesía y en poemas tales como "El Coloquio de los Centauros" parte de "Prosas Profanas" (1896) los tres Nocturnos, dos de ellos en "Cantos de Vida y Esperanza" (1905)y otro en "Canto Errante" (1906), en la "Dulzura del Ángelus", "Thánatos" y "Lo fatal"; por proponer una mínima red textual que posibilita un análisis. ${ }^{2}$

1 Escritor nicaragüense. e-mail : matesislogos@gmail.com

2 Darío, Rubén (1961): Obra poética completa. Madrid, Aguilar 


\section{Literatura}

Un género como es el nocturno de R. Darío, por cierto los retóricos dicen que los nocturnos son de la tradición musical y poética romántica, es en la poesía del maestro Darío, una forma adecuada para sus hondas reflexiones que muestran a donde llegó la intensidad de su existencia y las posibilidades de su mundo. La melopea dulce y evocadora hace necesaria la noche. La noche sacralizada por la poesía de Novalis es una raíz en estos nocturnos de Darío como ha demostrado ya Alfonso Martin Jiménez, ${ }^{3}$ pero es además el ambiente para los pensamientos sobre su propio existir. Rüdiger Safransky (2009) dice que para Novalis la noche simbolizaba la muerte, el absurdo, la ausencia, el vacío, el oscurecimiento, pero que al fin el amor triunfa sobre "la angustia de la muerte". ${ }^{4}$ En Darío la noche no es un escenario teatral ni espectral, es realmente la noche de la angustia.

Hay nocturnos como los de José Asunción Silva, famosos y con una resistencia al tiempo, pero se detienen en la meditación de la muerte de la amada con un fondo fantasmal. Los Nocturnos de Rubén Darío que también manifiestan la pérdida o el vacío de algo o de alguien, son elaborados no solo con una métrica o un ritmo de la palabra sino que revelan la angustia de un ser humano hipersensible que hace eco de la existencia humana. La angustia que tratan los poemas darianos citados es aquella que va más allá del miedo y del temor, es la angustia como una tonalidad afectiva presente que se experimenta ante la inminencia de la muerte y la nada que pende sobre todo existente. A veces esta angustia no tiene objeto, es insondable, no se determina qué es lo que angustia, si es por el mundo, la nada o la muerte por la que Darío siente un gran temor; en Darío hay temor y angustia, empero es la angustia la que devela su nada, le inquieta y le sume en ese temple de ánimo desde el que ve el mundo y siente en su interior una tormenta intracraneal. ${ }^{5}$

Si tomo como ejemplo el primer "Nocturno" que dice: "Quiero expresar mi angustia en versos que abolida/ dirán mi juventud de rosas y ensueños (...).
Lo primero que se observa es que la angustia está expresada en el presente y ligada a un pasado y un futuro y, por supuesto, a la muerte que Darío nombra como Ella. Recordemos que la angustia posibilita la apertura del si mismo, del encontrarse a si mismo. $Y$ esto es precisamente la característica de la angustia existencial propiamente dicha que se manifiesta en el tiempo o como en la temporeidad heideggeriana que no es el tiempo vulgar de los relojes, sino el de los éxtasis de la temporalidad por medio de los cuales vamos al pretérito o experimentamos el presente y nos proyectamos en el advenir que es lo que hace nuestro poeta Rubén Darío.

En el segundo Nocturno dedicado a Mariano de Cavia, una de las derivas es sentir que el tiempo es irredimible. En este nocturno el tiempo es causa de un pesar por lo que condicionó el pasado y la posible no existencia dada por el instante en que pudo no ser, todo esto en las posibilidades que constituyen nuestro mundo. Así mismo en este poema la refinada sensibilidad impresionista con que nos ambienta, los "ecos vagos" y los "ligeros ruidos", "cuando surgen de su prisión los olvidados". Igual en este texto, las agujas no marcan sino recuerdos y la pérdida de un reino que estaba para él. Tal vez en el nocturno permanece en una escritura insomne y Darío escribe las peripecias del insomnio. Es la hora de la lechuza como diría Jacques Derrida, momento propicio para la reflexión sobre los tiempos idos o el cavilar desde un presente angustiado.

El tercer Nocturno que es parte de "Canto Errante", tiende unos hilos a partir del tema axial de la angustia y el entorno de expectación y lo que tiene del Hamlet, personaje dubitativo y sombrío de William Shakespeare. El auto- Hamlet de Darío, es el desdoblamiento del auto análisis, "Ser la auto pieza/ de disección espiritual, el auto-Hamlet". Es el hablante que cavila sobre el si mismo, "cuando el ánima escucha y tiembla". El doloroso silencio nocturno no es más que la atmósfera doliente y tempórea que

3 Martin Jiménez, Alfonso: La noche en Novalis y en Rubén Darío. Los Himnos a la noche y Nocturno. En: Castilla, 20, 1995, 167-180.

4 Safransky, Rudiger(2009). Romanticismo. Una odisea del espíritu alemán. Barcelona, Tusquets.,111

5 Heidegger, Martin (1993). El Ser y el Tiempo. México DF, FCE. Parágrafo 40. 


\section{Literatura}

cerca al poeta y que es la llegada de la muerte que $R$. Darío transfigura en Ella, tal si fuese un fatal arcano femenino. Recordemos que la transformación de la muerte que Darío realiza es la del misterio inviolable. En "Coloquio de los Centauros" están esos bellos versos que dicen de la metamorfosis de la muerte: “ $\mathrm{i} a$ Muerte! Yo la he visto. No es demacrada ni mustia/ ni ase corva guadaña, ni tiene faz de angustia. /Es semejante a Diana, casta y virgen como ella; / en su rostro hay la gracia de la núbil doncella/y lleva una guirnalda de rosas siderales. En su siniestra tiene verdes palmas triunfales /y en su diestra un copa con agua del olvido. /A sus pies, como un perro, yace un amor dormido.

El poeta y ensayista Ernesto Gutiérrez mostró hace mucho tiempo la intertextualidad existente entre las obras de Rubén Darío y William Shakespeare, la relación directa entre el monólogo de Hamlet del acto III de Shakespeare y el nocturno dariano que referimos. ${ }^{6}$

Arturo Marasso en su libro "Rubén Darío y su creación poética", afirma que el ambiente de este Nocturno "Es la alta noche de Hamlet, de Shakespeare.", con un trasfondo del Libro de Job y de alguno de los Salmos de David, Marasso lo remite a una tradición hebraica de textos dolientes y autor reflexivos. ${ }^{7}$

Pero el propio Darío habla de sus Nocturnos con estas claras expresiones "y así exteriorizo en versos transparentes, sencillos y musicales, de música interior, los secretos de mi combatida existencia, los golpes de la fatalidad, las inevitables disposiciones del destino."

Julio Ycaza Tigerino en uno de sus magistrales escritos titulados "Los Nocturnos de Rubén Darío y otros ensayos" dice: "Pertenecen estos poemas de mi particular predilección a esa poesía de Rubén que toca los temas más universalmente humanos con la

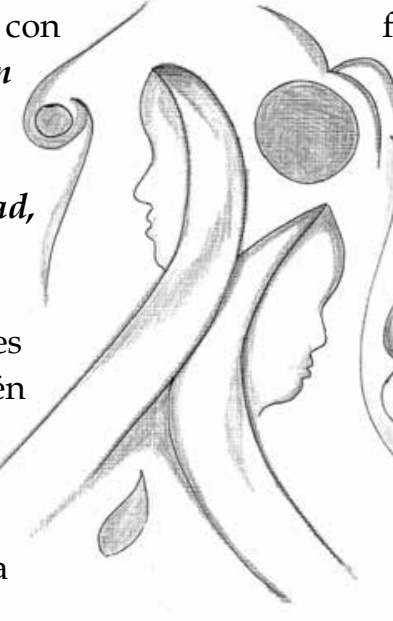

Autor: Jicksin López sensibilidad y la belleza propias de aquellos poetas que, por encima de los ciclos de la Cultura y de las fronteras idiomáticas, permanecen en la estimación de la Humanidad: un Goethe, un Shakespeare, un Lope, un Calderón." (Ycaza Tigerino:1967, 11 ).

"La dulzura del ángelus" es uno de los textos poéticos claves que revela la angustia y el spleen mientras las moiras tejen la madeja de un destino ineludible. Sin embargo, la fe da esperanza al hablante lírico en tanto suenan las campanas en la madrugada. Alguien dijo que en realidad lo que hay es una amarga dulzura de ángelus porque es un poema esplenético en que vence el hastío sobre la misma fe que el autor dice sostener, así lo ha mostrado Jorge Luis Castillo de la Universidad de California en su análisis titulado: "Del sentimiento esplenético de la vida. La amarga dulzura del ángelus de Rubén Darío" (2012). El verso que le sirve a este crítico es: "Y esta atroz amargura de no gustar nada" que según Castillo se corresponde con el esplín, con el vacío de sentido, con esa metafísica negativa del mundo moderno.

"Thánatos", poema cuyo título significa muerte, es evidente que Rubén Darío comprende con serenidad a la muerte como inevitable y ligada a la nada, pues lo dicen estos versos tan claros: " $Y$ no hay que aborrecer a la ignorada/ emperatriz y reina de la Nada". Como la ha dicho ya Martin Heidegger el ser -ahí muere fácticamente,la muerte es el fin del ser ahí, es siempre una posibilidad pero indeterminada, irreferente e irrebasable. Es decir, es posible morir ahora e imposible dejar de morir. Además vale recurrir a la frase de Heidegger de que "la muerte es el cofre de la nada" para realmente decir que un poeta como Darío piensa la nada tanto como el gran filósofo alemán que desarrolló toda una analítica existenciaria. ${ }^{9}$ Aún más, en este breve poema la muerte y la nada forman una bina temática, un tejido vital y existencial. De

6 Gutiérrez, Ernesto (1967): Rubén Darío y Shakespeare. Revista Conservadora. diciembre. 87. 22-35.

7 Marasso, Arturo. (1934). Rubén Darío y su creación poética. Biblioteca Nueva, Buenos Aires,1934.229-230.

8 Darío, Rubén (1988). Historia de mis libros. Editorial Nueva Nicaragua, Managua. 92,93.

9 Heidegger, Martin: La cosa. En: Conferencias y artículos, Serbal, Barcelona, 1994,143. 


\section{Literatura}

este poema Darío afirma "en Thánatos me estremezco ante lo inevitable."

En cuanto a "Lo fatal" que tiene toda la grandeza de un poema de la angustia por la muerte y el destino ignoto que nos espera, es para mí una esencial lección existencial que parte de la comprensión ontológica para elevarnos por encima de los entes y decirnos que la vida es una raíz de la existencia y no viceversa pues es el ser quien conoce el sentido de nuestro existir. Somos lo sido y lo que será, pero ignoramos el adónde vamos y el origen Autor: Jicksin López de dónde venimos. Sin embargo, se puede afirmar que lo que hay en el fondo es el ser para la muerte o delante de la muerte, la muerte temida y segura que acongoja el corazón de Rubén Darío.

En un artículo del académico e investigador dariano, Jorge Eduardo Arellano, titulado "Angustia existencial y vena filosófica en Rubén Darío “ (Septiembre,2010) es muy exacta la valoración que hace, cuando sostiene que " Lo fatal -una descarga agónica existencial-es un ejemplo lapidario de la poesía de la (des) esperanza que lleva a la angustia integrada por dos elementos esenciales de Darío: su obsesión ante la muerte y el terror a lo ignoto después de ella, es decir por el destino como escisión de su propio ser."

R. Darío dice a propósito de su poema: " $y$ en "Lo fatal" contra mi arraigada religiosidad, y a pesar mío, se levanta como una sombra temerosa un fantasma de desolación y de duda."11

Con todo esto no he querido más que llegar a algunas aseveraciones nacidas de los textos poéticos de Rubén Darío y lo primero es que no debemos ver a nuestro poeta solamente como un poeta trágico sino existencial. Lo existencial lo revela su poesía.

La angustia es apertura del mundo que permite a Darío evaluar su pasado, presente y su futuro, lo sitúa y lo conduce a expresar un pensamiento cierto sobre su propia muerte, la nada y el vacío. Si bien Darío teme a la

\section{Referencias}

Darío, Rubén (1961). Obra poética completa, Madrid, Aguilar.

Safransky, Rüdiger (2009). Romanticismo. Una odisea del espíritu alemán. Tusquets,

Barcelona.

Heidegger, Martin (1984).El Ser y el Tiempo. México, D.F, FCE.

Ycaza Tigerino, Julio (1954). Los Nocturnos de Rubén Darío y otros ensayos. Managua. Academia Nicaragüense de la Lengua.

Marasso, Arturo (1934). Rubén Darío y su creación poética. Buenos Aires, Biblioteca Nueva.

Darío, Rubén (1998). Historia de mis libros, Managua, Editorial Nueva Nicaragua.

Heidegger, Martin (1994). Conferencias y artículos. Barcelona, Serbal.

Ricouer, Paul (2003).El conflicto de las interpretaciones. Buenos Aires, Fondo de Cultura Económica Argentina.

12 Ricouer, Paul(2003).El conflicto de las interpretaciones. Fondo de Cultura Económica Argentina, Buenos Aires,2003.16 